\title{
Number of Ectopic Pregnancies
}

National Cancer Institute

\section{Source}

National Cancer Institute. Number of Ectopic Pregnancies. NCI Thesaurus. Code C120832.

A measurement of the total number of ectopic pregnancies experienced by a female subject. 